\title{
Present knowledge on pig Erysipelas (Erysipelothrix rhusiopathiae)
}

\author{
Josée VAISSAIRE *, Ph. DESMETTRE **, Geneviève PAILLE **, \\ Micheline LAROCHE*, Ginette MIRIAL * \\ * Ministère de l'Agriculture, Laboratoire Central de Recherches Vétérinaires \\ 22, rue Pierre-Curie, B.P. 67, 94703 Maisons-Alfort Cedex \\ ** Rhône Mérieux, Laboratoire I.F.F.A., 254, rue Marcel-Mérieux, 69007 Lyon
}

\begin{abstract}
A hundred years after the development of the first vaccinations against pig Erysipelas, this disease is well controlled particularly in the pig, but has not been totally eradicated. It is generally rapidly diagnosed by farmers and veterinarians which set up adequate curative and preventive treatments. They may even not appeal to the veterinary laboratory. The latter is required when the disease arise in vaccinated animals or in other animal species, particularly in poultry.

Eighty-six strains of Erysipelas having caused clinical symptoms have been studied since 1982. Thirty-three strains of Erysipelothris rhusiopathiae were isolated in pigs suffering from arthritis or from septicemia. Bacteriological and serological studies were conducted according to the methods developed by Wood et al. in the United States. Serotypes 2, 1a, 1b, 5, 6, 18 were found in the pig. Serotypes $2,1 \mathrm{a}, 1 \mathrm{~b}$ were most prevalent, whereas 5, 6, and 18 were found in small proportion. The latter were also detected in turkey and guinea fowl large herds which might constitute germe reservoir in areas of high pig production.

The efficiency of commercial vaccines which is obvious towards serotypes $2,1 \mathrm{a}$ and $1 \mathrm{~b}$ was tested towards serotypes $5,6,18$. The protection has not been totally evaluated, as the challenge strains issued from subcultures were not found pathogenic for the pig in our experimental conditions.

Further studies are in progress to control the serotypes of Erysipelothrix rhusiopathiae and to determine their pathogenicity as well as the possible increase in the germ virulence by passage in different animal species.
\end{abstract}

\section{A modified double antibody sandwich ELISA (enzyme-linked immunosorbent assay) for detection of TGEV (transmissible gastroenteritis coronavirus) and of specific antibodies}

\author{
S. BERNARD *, H. LAUDE **, I. LANTIER *, Elizabeth BOTTREAU *, \\ J.M. AYNAUD* \\ * I.N.R.A., Laboratoire de Pathologie Porcine, Nouzilly, 37380 Monnaie \\ ** Station de Virologie et d'Immunologie, 78850 Thiverval-Grignon
}

An enzyme-linked immunosorbent assay (ELISA) was developed for detection of antigens and antibodies to transmissible gastroenteritis virus (TGVE). The use of a «sandwich » technique involving mouse monoclonal antibodies and a pig polyclonal antibody conjugated to peroxydase allowed to detect TGEV antigens. Owing to this technique, it was possible to visualize antigens in TGEV-inoculated cell cultures as well as in the faeces or in intestınal lavage from an.mals inoculated with a virulent field strain.

The antibody classes in sow milk and serum were detected by a double sandwich technique which did not require the use of purified virus. However, in our experimental conditions, seroneutralization was more sensitive than ELISA. 